\title{
16-Channel CMOS Impedance Spectroscopy DNA Analyzer With Dual-Slope Multiplying ADCs
}

\author{
Hamed Mazhab-Jafari, Student Member, IEEE, Leyla Soleymani, and Roman Genov, Senior Member, IEEE
}

\begin{abstract}
We present a 16-channel, mixed-signal CMOS DNA analyzer that utilizes frequency response analysis (FRA) to extract the real and imaginary impedance components of the biosensor. Two computationally intensive operations, the multiplication and integration required by the FRA algorithm, are performed by an in-channel dual-slope multiplying ADC in the mixed-signal domain resulting in minimal area and power consumption. Multiplication of the input current by a digital coefficient is implemented by modulating the counter-controlled duration of the charging phase of the ADC. Integration is implemented by accumulating output digital bits in the ADC counter over multiple input samples. The $1.05 \mathrm{~mm} \times 1.6 \mathrm{~mm}$ prototype fabricated in a $0.13 \mu \mathrm{m}$ standard CMOS technology has been validated in prostate cancer DNA detection. Each channel occupies an area of only $0.06 \mathrm{~mm}^{2}$ and consumes $42 \mu \mathrm{W}$ of power from a $1.2 \mathrm{~V}$ supply.
\end{abstract}

Index Terms-Biosensor, DNA, electrochemical sensor, frequency response analysis, impedance spectroscopy, multiplying ADC.

\section{INTRODUCTION}

A NUMBER of integrated circuits for DNA detection on a disposable CMOS substrate platform have been introduced in recent years [1]-[7]. The on-chip electrochemical amperometric sensing DNA detection method shows promise over optical methods due to the real-time nature of DNA analysis [8]. Fig. 1 depicts a basic electrochemical cell employed in amperometric sensing. It consists of a working electrode (WE) and a reference electrode (RE). A transducer holds the working electrode at a known potential $V_{W E}$ while recording the redox current generated as a result of the voltage difference between the two electrodes. The reference electrode potential $V_{R E}$ is set to either a constant voltage for constant-potential amperometry, a bidirectional ramp voltage for cyclic voltammetry, or a small-amplitude sinusoid for impedance spectroscopy.

In biochemical sensors, biologically active compounds such as artificial antibodies, enzymes or receptors are integrated onto the working electrode. The integration process is performed by immobilization and stabilization of biological molecules

Manuscript received March 16, 2012; revised June 28, 2012 and September 03, 2012; accepted September 28, 2012. Date of publication November 20 , 2012; date of current version November 28, 2012. This paper was recommended by Associate Editor P. Hafliger.

H. Mazhab-Jafari and R. Genov are with the Department of Electrical and Computer Engineering, University of Toronto, Toronto, ON M5S 3G4, Canada (e-mail: hamed.mjafari@gmail.com; roman@eecg.utoronto.ca).

L. Soleymani is with McMaster University, Hamilton, ON L8S 4L8, Canada (e-mail: soleyml@mcmaster.ca).

Color versions of one or more of the figures in this paper are available online at http://ieeexplore.ieee.org.

Digital Object Identifier 10.1109/TBCAS.2012.2226334

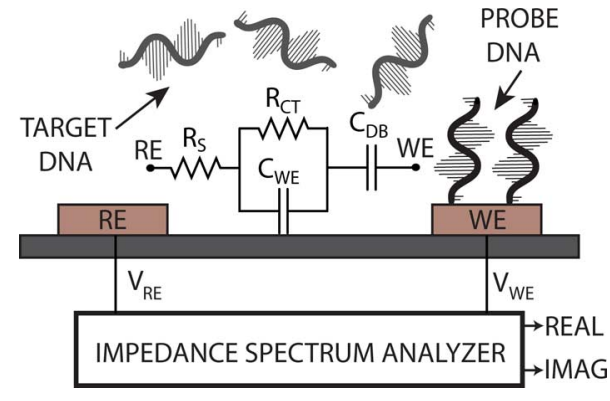

Fig. 1. Conceptual view of a biosensor impedance spectroscopy system.

on the electrode surface. In DNA sensing applications, the surface of the working electrode is functionalized with a probe DNA. Binding of the probe DNA with the target DNA results in a variation of the working electrode surface properties such as the impedance or the surface charge. The variation of the surface properties results in a change in the waveform features of the redox current, thus indicating changes in the kinetics and thermodynamics of the chemical reactions at the sensory interface [9]-[11]. In most applications, the recorded redox current is in the range of $\mathrm{pA}$ to $\mathrm{nA}$ and the biosensor frequency response covers a range of $1 \mathrm{~Hz}$ to $10 \mathrm{kHz}$ [13]-[17].

Impedance spectroscopy is a popular method of quantitative and qualitative monitoring of chemical reactions in many biosensors. A wide range of biosensors have been developed which rely on impedance spectroscopy, including sensors for detection of enzymes, antibodies and DNA [19], [20]. Fig. 1 also shows the basic principle of electrochemical impedance spectroscopy in DNA sensing applications. Binding of the probe DNA with the target DNA changes the impedance between the reference and the working electrodes. To detect this change, an impedance spectrum analyzer extracts the real and imaginary components of the biosensor impedance. A generic $R-C$ biosensor impedance model is depicted in Fig. 1. In this model $R_{S}$ represents the electrolyte resistance between the working and reference electrode, $C_{W E}$ represents the diffusion layer capacitance, $C_{D B}$ models the interfacial double-layer capacitance at the WE-electrolyte interface and $R_{C T}$ models the charge transfer resistance at the WE-electrolyte interface [21].

Several impedance spectroscopy integrated circuits have been reported [21]-[23]. The design in [22] is a single-channel impedance extractor based on a lock-in amplifier that extracts the sensor impedance from $1 \mathrm{~Hz}$ to $10 \mathrm{kHz}$. The implementation in [21] is a 100-channel impedance-to-digital converter based on a delta-sigma modulator capable of extracting sensor impedance from $1 \mathrm{mHz}$ to $10 \mathrm{kHz}$ at the expense of a long 
conversion cycle. A direct conversion receiver without an on-chip ADC [23] extracts the electrode impedance from 10 $\mathrm{Hz}$ to $50 \mathrm{MHz}$ at the cost of consuming $104 \mathrm{~mW}$ of power.

This paper presents a scalable, multi-channel, compact and low-power CMOS impedance spectroscopy DNA analyzer. Frequency response analysis (FRA) algorithm is utilized to extract the real and imaginary components of the biosensor impedance [24]. The proposed microsystem consists of a programable on-chip waveform generator and 16 impedance extraction channels. Each channel includes a current-mode input dual-slope multiplying ADC. It efficiently performs multiplication and integration, two computationally intensive operations required to implement the FRA algorithm. Multiplication of the input current by a digital coefficient is implemented by modulating the counter-controlled duration of the charging phase of the ADC by that coefficient. Integration is implemented by accumulating the output digital bits in the ADC counter. The dual-slope multiplying ADC utilizes mostly the same circuits as a conventional dual-slope ADC, and the multiplication and integration are achieved by modifying the $\mathrm{ADC}$ algorithm. The rest of the paper is organized as follows. Section II presents the principle of DNA detection on a CMOS die. Section III presents the impedance spectroscopy VLSI architecture. Section IV details the circuit implementation of the VLSI architecture. Section V demonstrates the electrical experimental results obtained from a $0.13 \mu \mathrm{m}$ CMOS prototype. In Section VI, results of on-chip impedance spectroscopy of DNA in prostate cancer screening are presented.

\section{DNA Detection PRinciple}

The principle of the label-free DNA detection method is shown in Fig. 2. It employs potassium ferrocyanide $\mathrm{K}_{4}\left[\mathrm{Fe}\left(\mathrm{CN}_{6}\right)\right]$ reporter. Potassium ferrocyanide is a negatively charged redox complex with well-defined electrochemical signature exhibiting oxidation and reduction currents at $V_{W E}-V_{R E}$ of $-450 \mathrm{mV}$ and $-200 \mathrm{mV}$ respectively [25]. The maximum electron transfer between the electrode and potassium ferrocyanide is achieved in the absence of DNA target and probe as illustrated in Fig. 2(a). The oxidization current $I_{O X}$ drops when the Au electrode surface is hybridized with negatively charged probe DNA, as illustrated in Fig. 2(b). When the complementary DNA binds with the probe DNA, the surface negative charge further increases and the oxidization current is further reduced, as shown in Fig. 2(c). This change in the current is an indicator of the target DNA presence and concentration. In other words, the presence of negatively charged DNA on the biosensor surface is translated to a decrease in the potassium ferrocyanide oxidation/reduction current creating a detectible signal change [26], [27].

The DNA sensing electrodes are created by first forming passivation openings on the top metal layer (aluminum) of the CMOS die similarly to how it is done for wire bond pads. Electroless electroplating is then employed to deposit nickel $(2 \mu \mathrm{m})$, palladium $(0.2 \mu \mathrm{m})$ and gold $(0.1 \mu \mathrm{m})$ on the exposed Al surface to form a bio-compatible electrode surface. After the electrode fabrication, the die is wire-bonded and the bonding wires are insulated with a biocompatible epoxy to enable

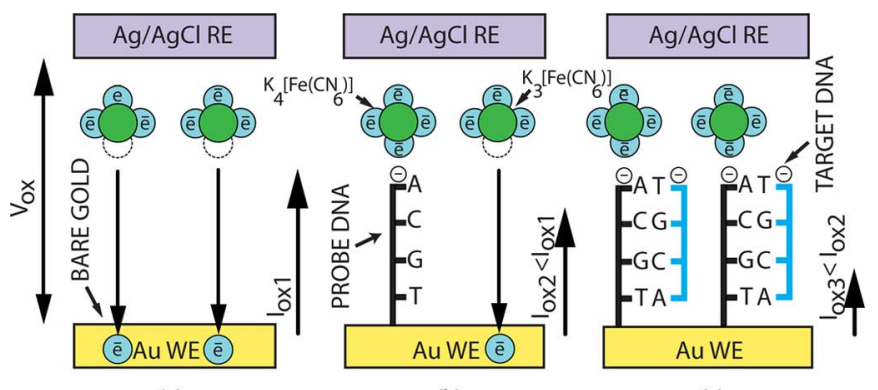

(a)

(b)

(c)

Fig. 2. Label-free electrochemical DNA detection principle.

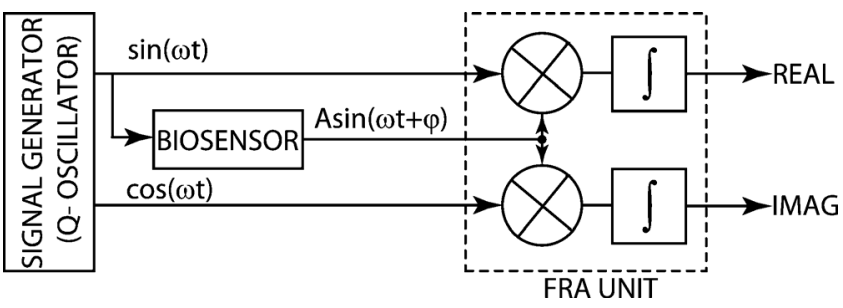

Fig. 3. Block diagram of a frequency-response analyzer (FRA) system for biosensor impedance spectroscopy.

on-chip electrochemical experiments without damaging the bonding wires [18].

\section{IMPEDANCE SPECTROSCOPY VLSI ARCHITECTURE}

A small-signal model of the electrode-electrolyte interface in an electrochemical cell is shown in the center of Fig. 1. Fast fourier transform (FFT) and frequency-response analyzer (FRA) are two methods widely used for characterizing the electrode impedance [24]. Compared to the FFT, the FRA method requires simple circuitry and can be implemented on a small silicon area, making it suitable for sensory array microsystems. A functional block diagram of the FRA algorithm is shown in Fig. 3. The sensor is interrogated with a sinusoidal voltage. Multiplication of the sensor response $A \sin (\omega t+\phi)$ with $\sin (\omega t)$ or $\cos (\omega t)$ and integration of the results over one cycle of the interrogation signal results in separation of the real and the imaginary components of the sensor impedance as follows [24]

$$
\begin{aligned}
\text { Real } & =\int_{0}^{T} A \sin (\omega t+\phi) \times \sin (\omega t) \mathrm{d} t, \\
& =\int_{0}^{T} 0.5 \times(A \cos (\phi)+\cos (2 \omega t+\phi)) \mathrm{d} t, \\
& =\frac{0.5 T}{\pi} \times A \cos (\phi) \\
\text { Imag } & =\int_{0}^{T} A \sin (\omega t+\phi) \times \cos (\omega t) \mathrm{d} t, \\
& =\int_{0}^{T} 0.5 \times(A \sin (\phi)+\sin (2 \omega t+\phi)) \mathrm{d} t, \\
& =\frac{0.5 T}{\pi} \times A \sin (\phi)
\end{aligned}
$$

where $A$ represents the amplitude, $\phi$ represents the phase of the sensor impedance and $T$ is the period of the interrogation 


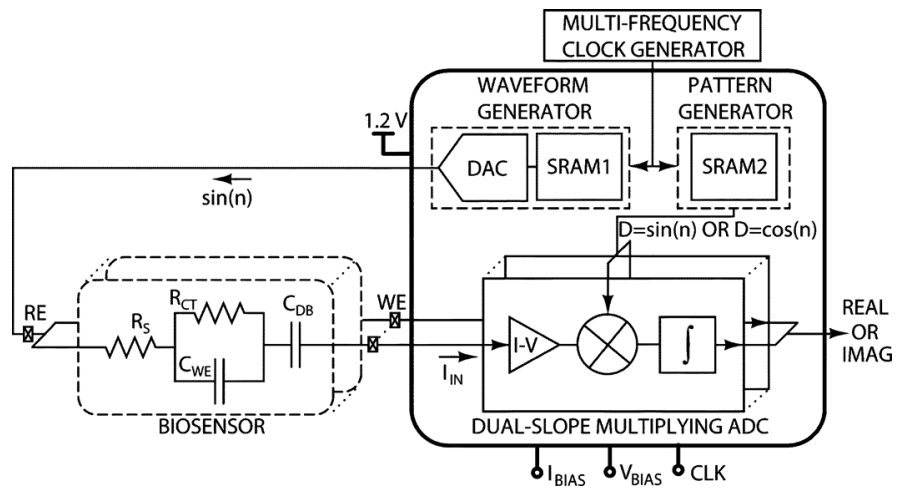

Fig. 4. Impedance spectroscopy microsystem functional block diagram.

signal. $A \cos (\phi)$ is the real portion and $A \sin (\phi)$ is the imaginary portion of the sensor impedance. These values over a wide frequency range are sufficient to fully describe the sensor impedance.

In this work the FRA algorithm has been chosen to implement a sensory array impedance spectroscopy microsystem. The two key components in this system are the multiplier and the digital integrator. Both of these operations are implemented with an in-channel multiplying dual-slope ADC that reuses the circuits of a conventional dual-slope ADC [28].

\section{CiRCUIT IMPLEMENTATION}

\section{A. Multi-Channel System-Level Architecture}

The functional block diagram of the impedance spectroscopy microsystem based on the FRA algorithm is shown in Fig. 4. The microsystem is comprised of a programable analog waveform generator, a programmable digital pattern generator and an array of impedance extraction units. The waveform generator produces the interrogation waveform $\sin (\omega t)$ and drives the reference electrode with it. The digital pattern generator generates digital multiplication coefficients representing either sine wave or cosine wave that are synchronized with the interrogation waveform. Each impedance extraction unit consists of a dual-slope multiplying ADC (DS-MADC). The front-end current-to-voltage converter is an analog integrator that acquires an input current at the low-impedance input node set to a controlled potential. The DS-MADC multiplies the biosensor response $I_{\mathrm{IN}}$ with a set of digital coefficients $D$ representing $\sin (\omega t)$ or $\cos (\omega t)$ that are synchronized with the analog sinusoidal interrogation voltage on the reference electrode. Next the DS-MADC accumulates the results over one period of the interrogation signal using a digital integrator (counter), thus extracting the real or the imaginary components of the biosensor impedance.

\section{B. Waveform Generator and Pattern Generator}

The frequency response analysis implementation is the simplest when rectangular waveforms are used instead of sine wave for both the interrogation and the multiplication signals. The problem is that severe systematic errors appear due to the higher order harmonics existing in the rectangular waveforms. Stepwise approximation of the interrogation waveform and the multiplication signals reduces the effect of higher order harmonics

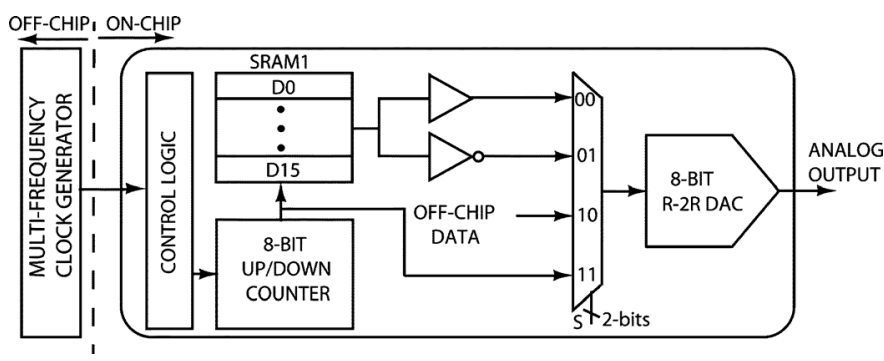

Fig. 5. Waveform generator functional block diagram.

and increases the measurement accuracy. It has been shown [22] that representing both the interrogation signal and the multiplication signals by a coarsely quantized approximation can significantly reduces the error due to the higher order harmonics and can significantly reduce the measurement inaccuracy.

In this work a programmable analog waveform generator is utilized to generate the stepwise approximation of the interrogation signal. The block diagram of the programmable waveform generator is shown in Fig. 5. It is composed of an 8-bit R-2R DAC, an on-chip SRAM1 and a bidirectional counter. The DAC coefficients are stored in the on-chip SRAM1. The on-chip waveform generator generates both stepwise sinusoidal and cyclic voltammetry (CV) ramp waveforms. It provides a wide range of user-controlled rate and amplitude parameters with a maximum $\mathrm{CV}$ scan range of $1.2 \mathrm{~V}$, and scan rate ranging between $0.1 \mathrm{mV} / \mathrm{sec}$ to $400 \mathrm{~V} / \mathrm{sec}$ and the sinusoidal frequency range from $100 \mathrm{mHz}$ to $50 \mathrm{kHz}$. An off-chip clock generator provides the variable frequency clock signal enabling the waveform generator to generate the interrogation signal at different frequencies. The DAC occupies an area of $0.012 \mathrm{~mm}^{2}$ and dissipates $1.1 \mathrm{~mW}$ of power from a $1.2 \mathrm{~V}$ supply when driving a load of $5 \mathrm{nF}$ at $50 \mathrm{kHz}$. At low frequencies the interrogation sine wave is represented by 64 samples per period. The DAC coefficients for the first 16 samples ( $D_{0}$ to $D_{15}$ ) of the waveform generator output waveform and for the corresponding digital $\sin / \cos$ multiplication coefficients are stored in two on-chip global SRAM banks (SRAM1 and SRAM2, respectively), as shown in Fig. 4. The SRAMs occupy an area of $0.028 \mathrm{~mm}^{2}$ and dissipate $0.9 \mu \mathrm{W}$ of power when clocked at $50 \mathrm{kHz}$. By symmetry, 64 samples in one period are generated from the 16 samples stored on-chip. As shown in Fig. 6, for a sine wave, the first 16 samples stored in the SRAM1 generates the first quadrant of the sine wave. In this case the counter controlling the SRAM1 is counting up and $S$ is set to 00 , in Fig. 5. In the next quadrant the counter controlling the SRAM1 counts down thus reversing the order of the samples and generating the second quadrant of the sine wave. $S$ is set to 00 in this case. The third and forth quadrants are generated in the same manner but in this case the polarities of the samples fed into the DAC are reversed (by setting $S$ to 01$)$. To generate a cosine, the cycle starts from the second quadrant instate of the first one. If a $\mathrm{CV}$ waveform is required the up/down counter is directly interfaced to the waveform generator DAC (by setting $S$ to 11).

As the interrogation frequency increases, the number of samples representing the interrogation and multiplication signals decreases and at $10 \mathrm{kHz}$ both signals are represented by three 


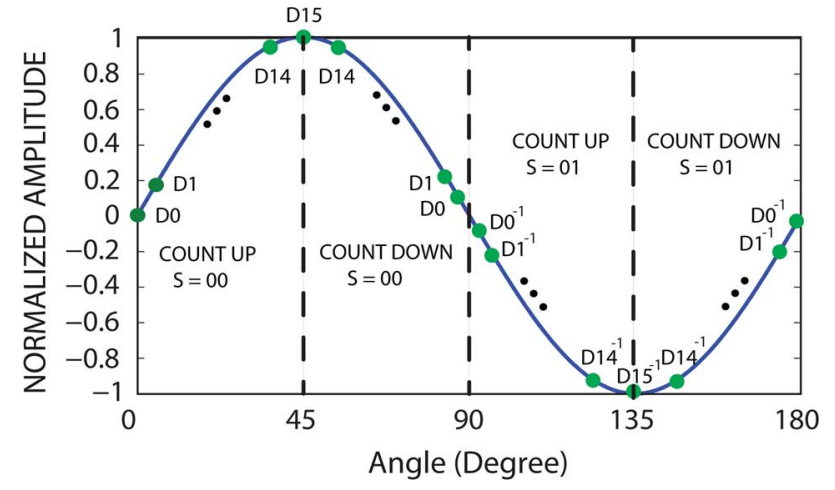

Fig. 6. Principle of the sine wave generation.

samples. This greatly reduces the ADC speed requirement while the error caused by the reduction in number of samples is kept low by averaging the results over multiple cycles.

An ideal model of the impedance spectroscopy microsystem has been constructed using verilog-A model components (ideal analog integrator and multiplying $\mathrm{ADC}$ ) to study the effect of step-wise approximation of the interrogation signal on the overall system accuracy. First a simulation was performed where a sinusoidal voltage stimulus (8-bit accurate generated by an ideal DAC) with the frequency swept from $0.1 \mathrm{~Hz}$ to $10 \mathrm{kHz}$ was applied to the biosensor model shown in Fig. 4. The value of $R_{S}$ was set to $1 \mathrm{G} \Omega, C_{W E}$ was set to $500 \mathrm{pF}$, $C_{D B}$ was set to $300 \mathrm{pF}$ and $R_{C T}$ was set to $1 \mathrm{M} \Omega$. The sensor response was recorded with the ideal analog integrator and multiplied, using an ideal multiplying dual-slope ADC, by an 8-bit accurate digital multiplication coefficient representing sine or cosine in the FRA algorithm in Fig. 3. Next, the same set of simulations were performed in which both digital multiplication coefficients and the analog sinusoidal voltage interrogation signal are represented by 64 samples per period at low frequencies. In this simulation as the interrogation frequency increases, the number of samples representing the interrogation and multiplication signals decreases. Also, in this simulation the results are averaged over multiple cycles $(N)$ to reduce the errors caused by reduction in the number of samples. The absolute value of the relative error of the biosensor impedance computed using 8-bit accurate interrogation signal and 8-bit accurate multiplication coefficients versus the simulated biosensor impedance obtained from stepwise approximation of these signals is shown in Fig. 7. The absolute value of the relative error stays below $0.9 \%$ and $1.0 \%$ for real and imaginary component of the biosensor, respectively.

\section{Dual-Slope Multiplying ADC Channel}

The VLSI architecture of one channel of the integrated spectrum analyzer is depicted in Fig. 8(a). Each channel consists of an integrating amplifier with an on-chip $10 \mathrm{pF}$ capacitor $C_{F}$, a high-speed latched comparator and digital blocks. The integrator switches are implemented with low-leakage switches as shown.

The conventional dual-slope ADC operates in two phases as depicted in Fig. 9. In phase I the integrating capacitor $C_{F}$ is charged for a predetermined period of time $T_{1}$. Next, during the

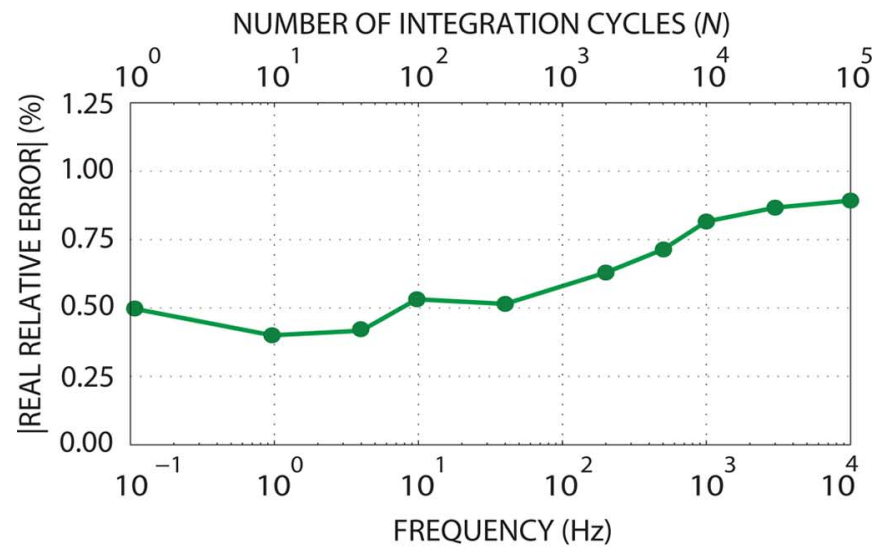

(a)

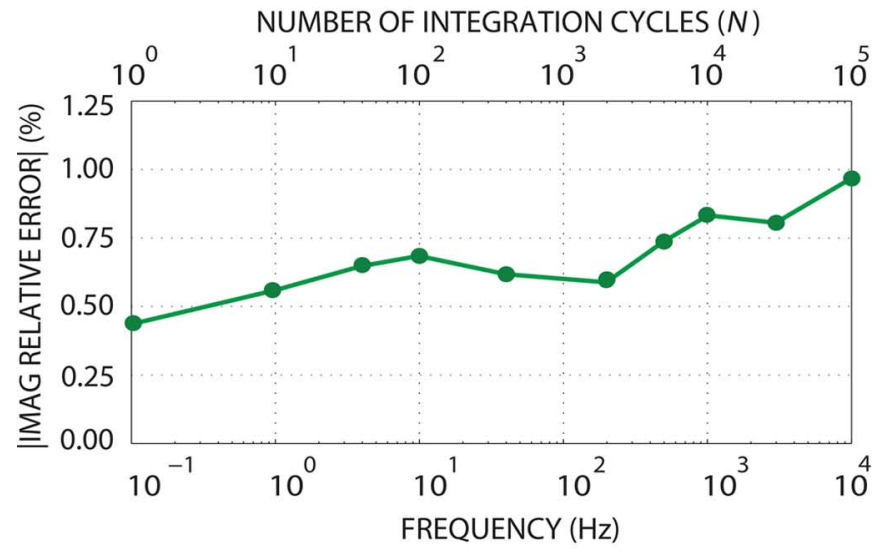

(b)

Fig. 7. Absolute value of the relative error of the biosensor $R-C$ model impedance as a function of frequency due to stepwise approximation of the interrogation signal for the (a) real and (b) imaginary components.

second phase of the operation, the capacitor is discharged to zero by a DC reference current. By counting the time $T_{2}$, a digital representation of $I_{\mathrm{IN}}$ can thus be obtained as $\left(T_{2} / T_{1}\right) \times I_{R E F}$. To implement multiplication of the input current by a digital $\sin / \cos$ coefficient $\left(D_{1}\right.$ to $\left.D_{15}\right)$ as needed by the FRA algorithm, the duration of phase I is scaled with a constant coefficient $D<1$ as shown in Fig. 9. In this case by counting the time $D T_{2}$, a digital representation of $D I_{\mathrm{IN}}$ can be obtained as $D \times\left(T_{2} / T_{1}\right) \times I_{R E F}$. To extract the real and imaginary components of the biosensor impedance, the input current $I_{\mathrm{IN}}$ is multiplied by the reference sine or cosine digital coefficient denoted as $D$ (stored in SRAM2, in Fig. 4) and the results are integrated over one period by a 16-bit counter as follows:

$$
\begin{aligned}
\text { Real } & =\int_{0}^{T} I_{\mathrm{IN}} \times \sin (\omega t) d t \\
& =\sum_{1}^{N / 2} I_{\mathrm{IN}} \times|\sin [n]|-\sum_{N / 2+1}^{N} I_{\mathrm{IN}} \times|\sin [n]| \\
\text { Imag } & =\int_{0}^{T} I_{\mathrm{IN}} \times \cos (\omega t) d t \\
& =\sum_{1}^{N / 2} I_{\mathrm{IN}} \times|\cos [n]|-\sum_{N / 2+1}^{N} I_{\mathrm{IN}} \times|\cos [n]|
\end{aligned}
$$




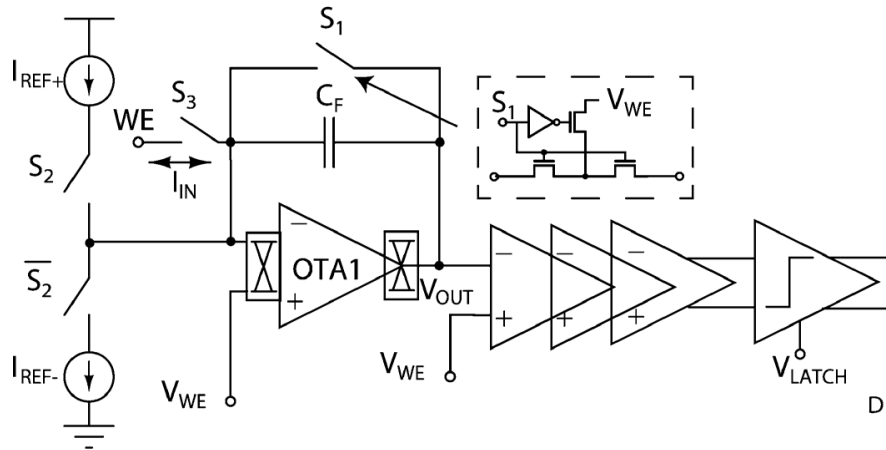

(a)

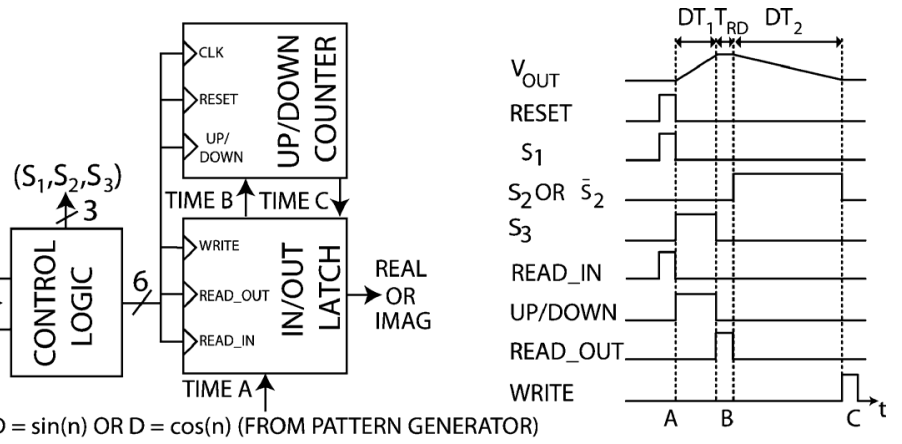

(b)

Fig. 8. (a) Dual-slope multiplying ADC VLSI architecture. (b) Timing diagram of all relevant signals.

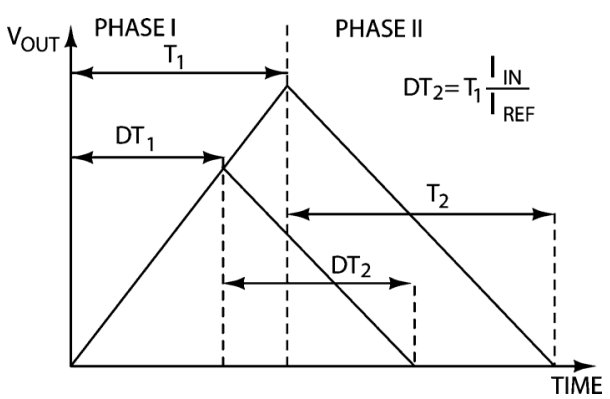

Fig. 9. Timing diagram illustrating the ADC multiplication function.

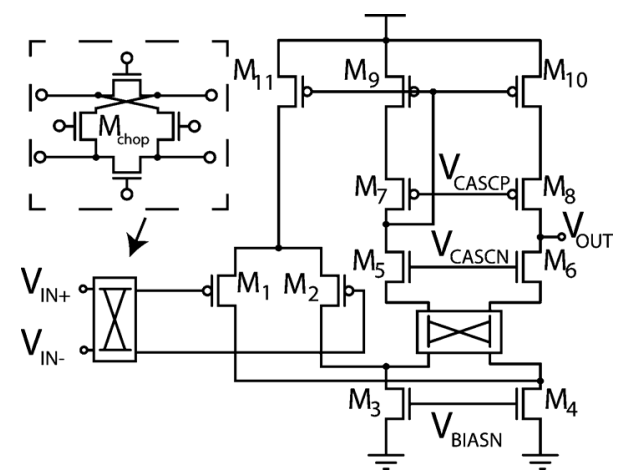

Fig. 10. Chopper-stabilized folded-cascode OTA1 in the analog integrator.

where $N$ is the number of samples in one period and $\sin [n]$ and $\cos [n]$ are the digital multiplication coefficients $D$ that are stored in the SRAM2. The multiplying dual slope ADC performs the multiplication required by (3) and (4), thus the need for 16 digital multipliers is eliminated.

The timing diagram of the ADC for a typical conversion cycle is shown in Fig. 8(b). First, the integrating counter is reset. At the same time, the $\sin /$ cos multiplication coefficient, $D$, is loaded into the in-channel input latch (time A). Next, the in-channel counter counts up from zero to time $D T_{1}$ and the input current is integrated onto capacitor $C_{F}$. After time $D T_{1}$, the voltage on the capacitor is held constant for a fixed time interval $T_{R D}$. During this time the content of the output latch (zero for the first conversion cycle) is loaded into the counter (time B). During time $D T_{2}$, depending on the comparator

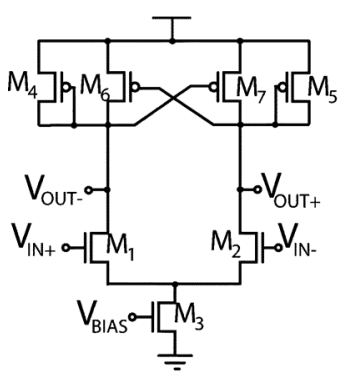

(a)

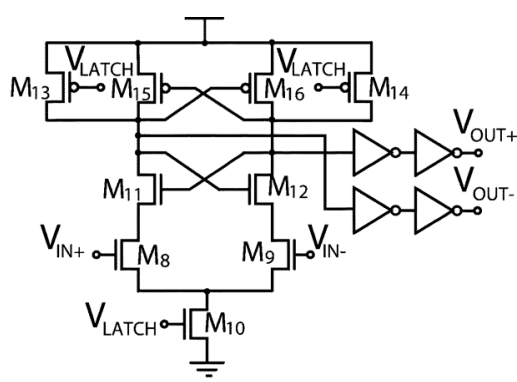

(b)
Fig. 11. Comparator circuit diagram. (a) One of the three identical gain stages. (b) The high-speed latch.

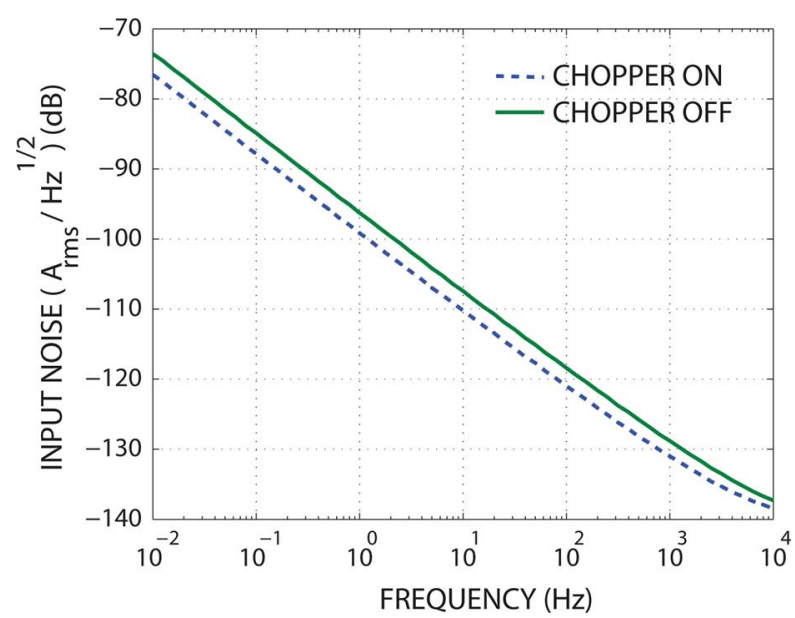

Fig. 12. Simulated input-referred noise spectrum of the analog integrator with the chopper on and off (clocked at $100 \mathrm{kHz}$ ) from $0.01 \mathrm{~Hz}$ to $10 \mathrm{kHz}$.

output, the integrating capacitor is discharged using the appropriate current source, $I_{R E F+}$ or $I_{R E F-}$. During time $D T_{2}$ the counter counts up or down depending on the sign of the input current in phase I and the final value of the counter is written into the output latch (time $\mathrm{C}$ ). This part of the ADC conversion cycle performs the summation which implements integration required by the FRA algorithm. This process is repeated for one full cycle of the sinusoidal stimulation waveform and the final value stored in the output latch corresponds to the real or imaginary component of the biosensor impedance, for sin and cos multipliers respectively. 


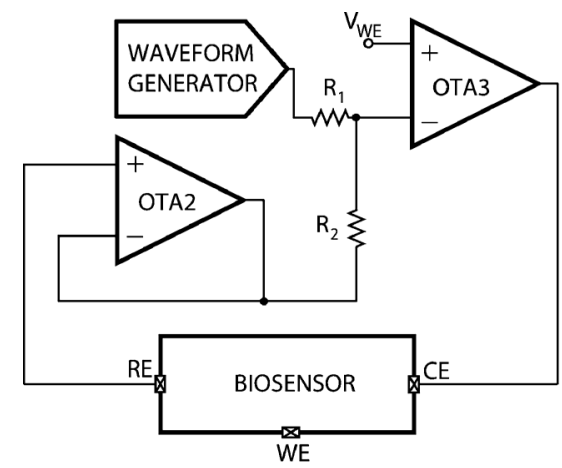

(a)

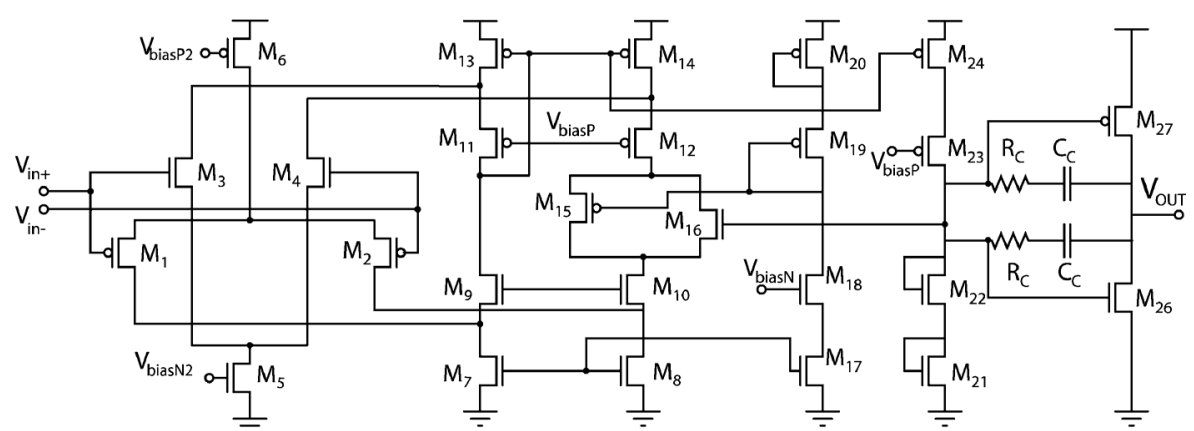

(b)

Fig. 13. (a) Circuit architecture of the three-electrode regulation loop. (b) OTA2 and OTA3 circuit schematic.

TABLE I

OTA1 AND COMPARATOR TRANSISTOR SIZING

\begin{tabular}{cccc}
\hline $\begin{array}{c}\text { OTA1 } \\
\text { Transistor }\end{array}$ & W/L $(\mu m)$ & $\begin{array}{c}\text { Comparator } \\
\text { Transistor }\end{array}$ & W/L $(\mu m)$ \\
\hline$M_{1,2}$ & $8 \times 3 / 1$ & $M_{1,2}$ & $12 \times 12 / 0.2$ \\
$M_{3,4}$ & $2 \times 1 / 4$ & $M_{3}$ & $3 \times 2 / 4$ \\
$M_{5,6}$ & $4 \times 1 / 1$ & $M_{4,5}$ & $2 \times 1.5 / 0.4$ \\
$M_{7,8}$ & $8 \times 1 / 1$ & $M_{6,7}$ & $2 \times 1.5 / 0.4$ \\
$M_{9,10}$ & $4 \times 1 / 4$ & $M_{8,9}$ & $6 \times 6 / 0.5$ \\
$M_{11}$ & $8 \times 1 / 2$ & $M_{10}$ & $3 \times 2 / 4$ \\
- & - & $M_{11,12}$ & $6 \times 6 / 0.5$ \\
- & - & $M_{13,14}$ & $2 \times 1.5 / 1$ \\
\hline
\end{tabular}

The analog integrator amplifier shown in Fig. 10 is a foldedcascode transconductance amplifier consuming $6 \mu \mathrm{W}$ from a $1.2 \mathrm{~V}$ supply. Impedance spectroscopy is performed over the frequency range of $1 \mathrm{~Hz}$ to $10 \mathrm{kHz}$. To reduce the effect of flicker noise, the amplifier utilizes input PMOS devices with a high aspect ratio and internal chopping. As shown in Fig. 10, the chopper switches are placed at the input of the OTA. Another set is placed between the cascoded NMOS current mirrors. This significantly reduces the flicker noise and DC offsets caused by the input pair transistors and the NMOS current mirror transistors.

The simulated input-referred noise of the integrator for the cases where the chopper is disabled and enabled is shown in Fig. 12. The integrated input-referred noise from $0.01 \mathrm{~Hz}$ to $10 \mathrm{kHz}$ is $0.12 \mathrm{pA}$ when the chopper is disabled and $0.07 \mathrm{pA}$ when the chopper is enabled. The integrator transistor sizes are shown in Table I. Contribution of each transistor to the total input-referred noise is shown Table II. When the chopper is disabled the main contributions are from the OTA current mirror transistors $M_{3}$ and $M_{4}$ and the input pair transistors $M_{1}$ and $M_{2}$. When the chopper is enabled, the current mirror transistors $\mathrm{M}_{9}$ and $\mathrm{M}_{10}$ are the main contributors to the input-referred noise.

The comparator is implemented with three pre-amplifier stages [Fig. 11(a)], with a total gain of $60 \mathrm{~dB}$, and a high-speed output latch as shown in Fig. 11(b). The comparator is verified in simulation to operate at up to $40 \mathrm{MHz}$. The full channel consumes $42 \mu \mathrm{W}$ of power from a $1.2 \mathrm{~V}$ supply when clocked at $10 \mathrm{MHz}$. The comparator transistor sizes are shown in Table I.
TABLE II

ANALOG INTEGRATOR NOISE SUMMARY

\begin{tabular}{cccc}
\hline Transistor & $\begin{array}{c}\text { Noise } \\
\text { Source }\end{array}$ & $\begin{array}{c}\text { Total Noise, } \\
\text { Chopper OFF }\end{array}$ & $\begin{array}{c}\text { Total Noise, } \\
\text { Chopper ON }\end{array}$ \\
\hline$M_{3,4}$ & Flicker & $26.4 \%$ & $11.02 \%$ \\
$M_{1,2}$ & Flicker & $22.1 \%$ & $10.3 \%$ \\
$M_{3,4}$ & Thermal & $21.2 \%$ & $23.4 \%$ \\
$M_{1,2}$ & Thermal & $18.3 \%$ & $22.1 \%$ \\
$M_{9,10}$ & Flicker & $5.25 \%$ & $17.50 \%$ \\
$M_{9,10}$ & Thermal & $3.26 \%$ & $8.26 \%$ \\
$M_{5,6}$ & Flicker & $1.1 \%$ & $3.38 \%$ \\
$M_{7,8}$ & Flicker & $1.04 \%$ & $1.19 \%$ \\
$M_{5,6}$ & Thermal & $0.9 \%$ & $1.0 \%$ \\
$M_{7,8}$ & Thermal & $0.8 \%$ & $0.9 \%$ \\
\hline
\end{tabular}

TABLE III

OTA2 AND OTA3 TRANSISTORS SIZING

\begin{tabular}{cccc}
\hline Transistor & W/L $(\mu m)$ & Transistor & W/L $(\mu m)$ \\
\hline$M_{1,2}$ & $6 \times 2 / 6$ & $M_{16}$ & $1 \times 1.2 / 1$ \\
$M_{3,4}$ & $2 \times 1.5 / 0.4$ & $M_{17}$ & $1 \times 1.2 / 1$ \\
$M_{5,6}$ & $2 \times 1.5 / 0.4$ & $M_{18}$ & $1 \times 1.2 / 1$ \\
$M_{7,8}$ & $3 \times 2 / 0.12$ & $M_{19,20}$ & $1 \times 1.2 / 1$ \\
$M_{9,10}$ & $3 \times 2 / 0.12$ & $M_{21,22,23,24}$ & $3 \times 2 / 0.12$ \\
$M_{11}$ & $1 \times 1.2 / 1$ & $M_{25}$ & $3 \times 2 / 0.12$ \\
$M_{12,13,14,15}$ & $3 \times 2 / 0.12$ & $M_{26}$ & $1 \times 1.2 / 1$ \\
$M_{9,10}$ & $3 \times 2 / 0.12$ & & \\
\hline
\end{tabular}

\section{Three-Electrode Regulation Loop}

The functional block diagram of the regulation loop is shown in Fig. 13(a). A three-electrode potentiostat configuration [29] is employed as opposed to the basic two-electrode configuration shown in Fig. 1. In a two-electrode configuration the current flowing between the two electrodes alters the voltage drop across $\mathrm{C}_{D B}$ due to the non-zero impedance of the electrolyte solution and the electrode-electrolyte interface. In the three-electrode configuration, a third, counter electrode $(\mathrm{CE})$, rather than the reference electrode is placed in the current path. The reference electrode does not sink/source an electric current. Thus the voltage difference between the working and reference electrode is maintained at a known voltage independent of the electrochemical cell impedance. The three-electrode regulation loop is composed of the two OTAs as shown in Fig. 13(a). To allow for wide input and output swings class-AB OTAs with both NMOS and PMOS input differential pairs are used for the potentiostat as shown in Fig. 13(b). OTA transistor sizing is given 


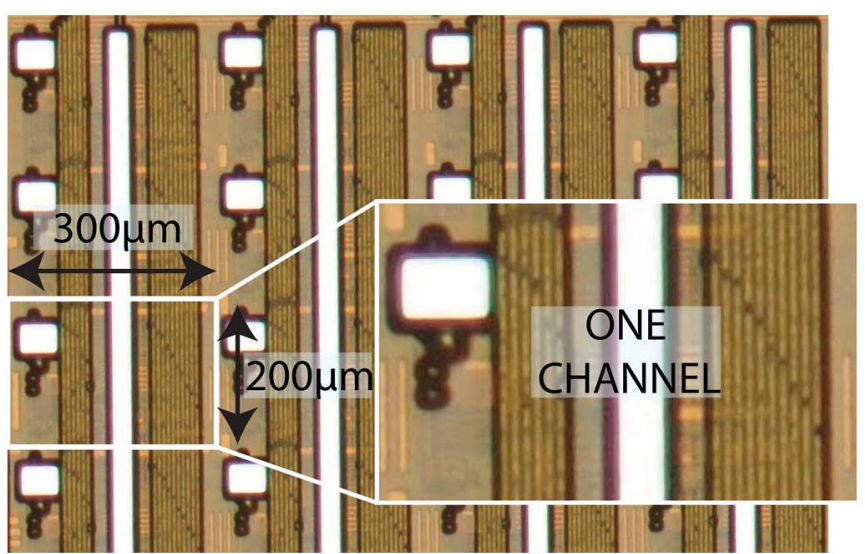

Fig. 14. Die micrograph of the $1.05 \mathrm{~mm} \times 1.6 \mathrm{~mm} \mathrm{16-channel} \mathrm{integrated}$ impedance spectrum analyzer fabricated in a $0.13 \mu \mathrm{m}$ standard CMOS technology.

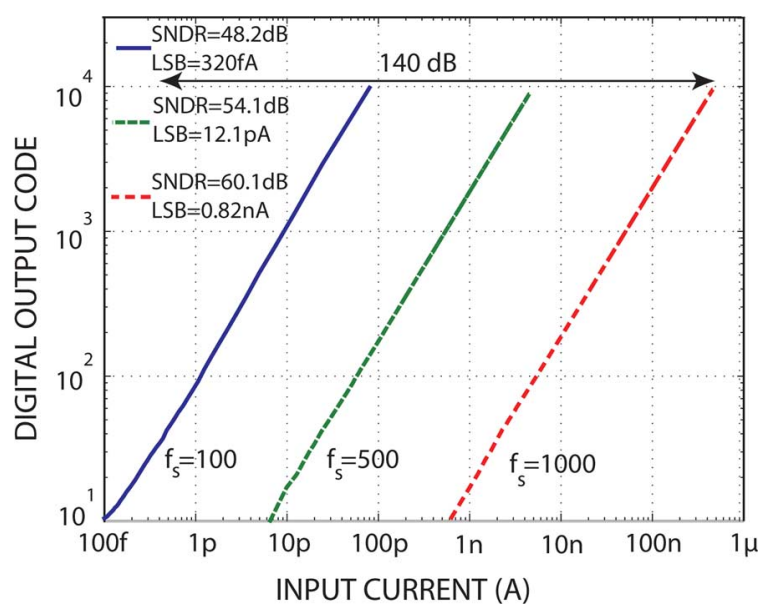

Fig. 15. Experimentally measured transfer characteristics of the impedance spectrum analyzer channel for three sampling frequencies.

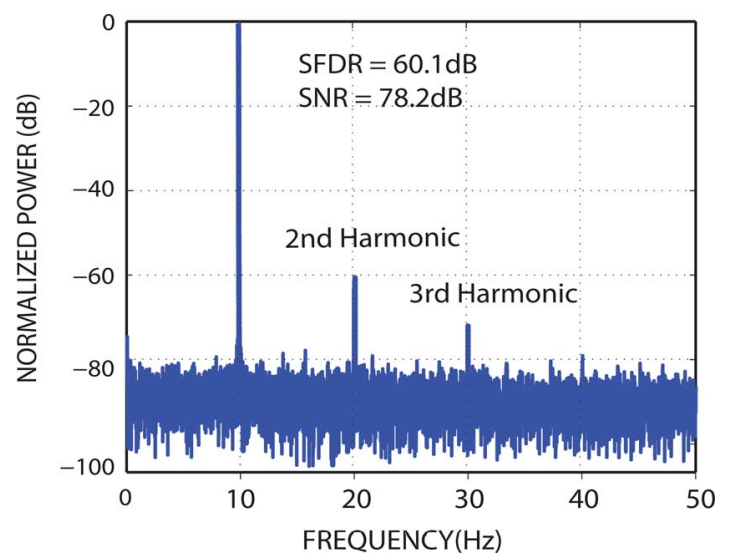

Fig. 16. Experimentally measured output spectrum of the ADC for a $10 \mathrm{~Hz}$ sinusoidal input.

in Table III. Assuming that $\mathrm{V}_{W E}$ is fixed by the analog integrator, the regulation loop configuration ensures that $V_{R E}-$ $V_{W E}$ tracks the voltage difference between the output of the waveform generator and the positive terminal of the OTA3.

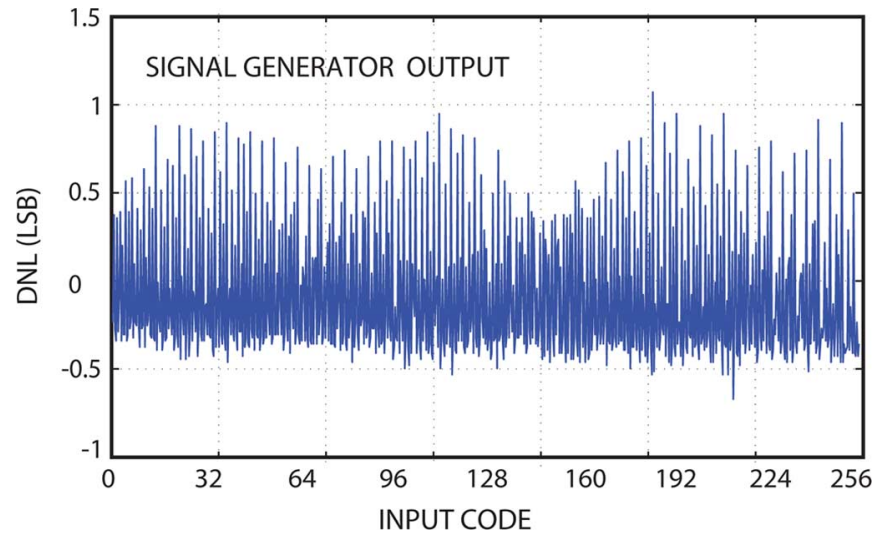

Fig. 17. Waveform generator DNL.

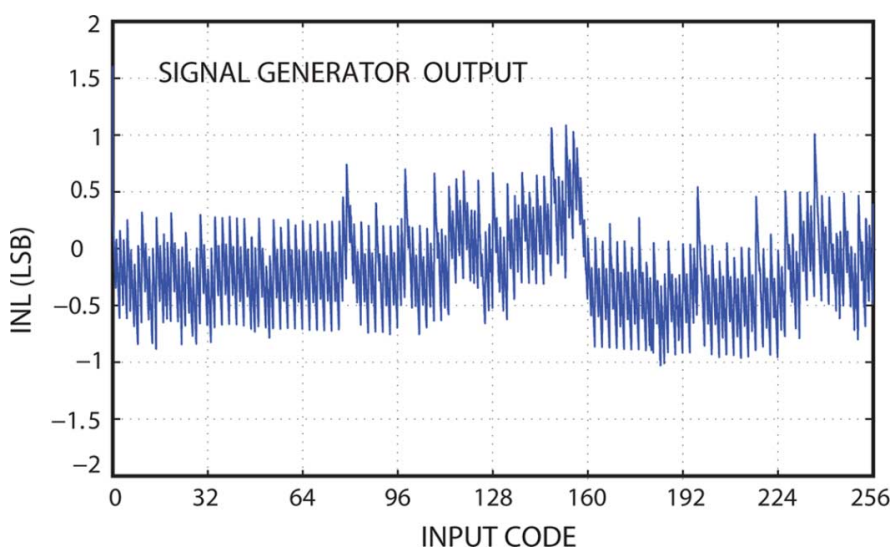

Fig. 18. Waveform generator INL.

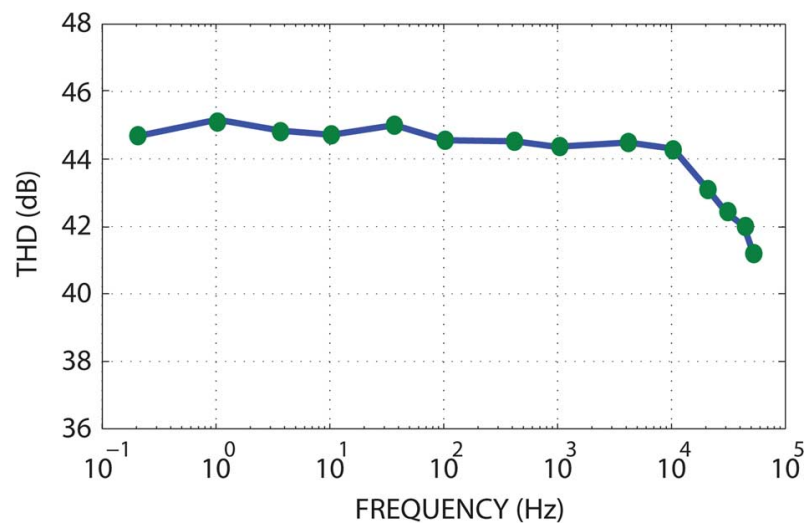

Fig. 19. Total harmonic distortion of waveform generator DAC.

\section{ELECTRICAL EXPERIMENTAL RESULTS}

The 16-channel $1.2 \times 1.6 \mathrm{~mm}^{2}$ integrated impedance spectrum analyzer prototype was implemented in a $0.13 \mu \mathrm{m} \mathrm{CMOS}$ process with a $1.2 \mathrm{~V}$ supply. The die micrograph is shown in Fig. 14. Each channel consists of 4 WEs, with different WE sizes ( $55 \mu \mathrm{m} \times 55 \mu \mathrm{m}, 5 \mu \mathrm{m} \times 5 \mu \mathrm{m}$, and two $2 \mu \mathrm{m} \times 2 \mu \mathrm{m}$ ) to cover a wide combined dynamic range. Each column of four working electrodes shares a $45 \mu \mathrm{m}$-wide Au reference and counter electrodes driven by the on-chip waveform generator. Each channel consists of the analog integrator, dual-slope multiplying ADC and in-channel bias and clock generator. Each channel WE can 
TABLE IV

EXPERIMENTALLY MEASURED CHARACTERISTICS

\begin{tabular}{lc}
\hline Technology & $0.13 \mu \mathrm{m} \mathrm{CMOS}$ \\
Supply Voltage & $1.2 \mathrm{~V}$ \\
Area & $1.05 \mathrm{~mm} \times 1.6 \mathrm{~mm}$ \\
Array Dimensions & $4 \times 4$ channels \\
Channel Size & $300 \mu \mathrm{m} \times 200 \mu \mathrm{m}$ \\
Sensitivity & $320 \mathrm{fA}$ \\
Channel SNR $\left(\mathrm{f}_{c l k}=10 \mathrm{MHz}\right)$ & $78.2 \mathrm{~dB}$ \\
Channel SFDR $\left(\mathrm{f}_{c l k}=10 \mathrm{MHz}\right)$ & $60.1 \mathrm{~dB}$ \\
Power Consumption & \\
DAC & $1.1 \mathrm{~mW}$ \\
SRAM & $1.3 \mu \mathrm{W}$ \\
Analog Integrator & $8 \mu \mathrm{W}$ \\
Comparator & $19 \mu \mathrm{W}$ \\
Biasing & $4 \mu \mathrm{W}$ \\
Digital & $11 \mu \mathrm{W}$ \\
Total (channel) & $42 \mu \mathrm{W}$ \\
\hline
\end{tabular}

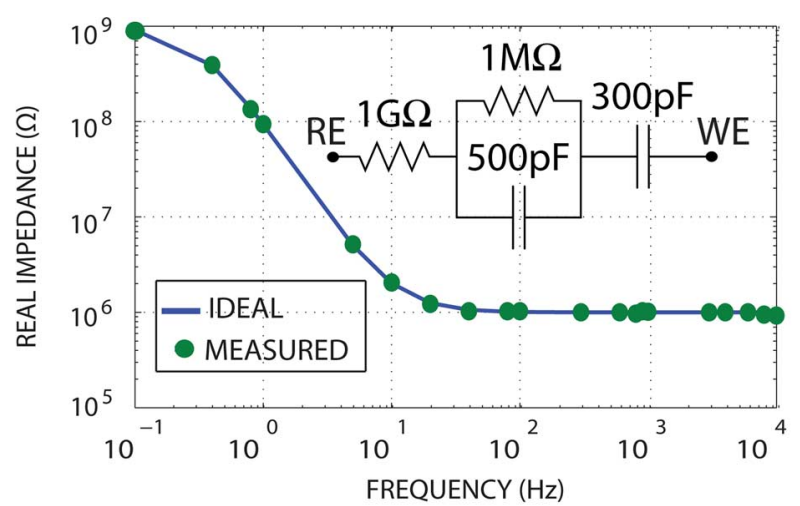

(a)

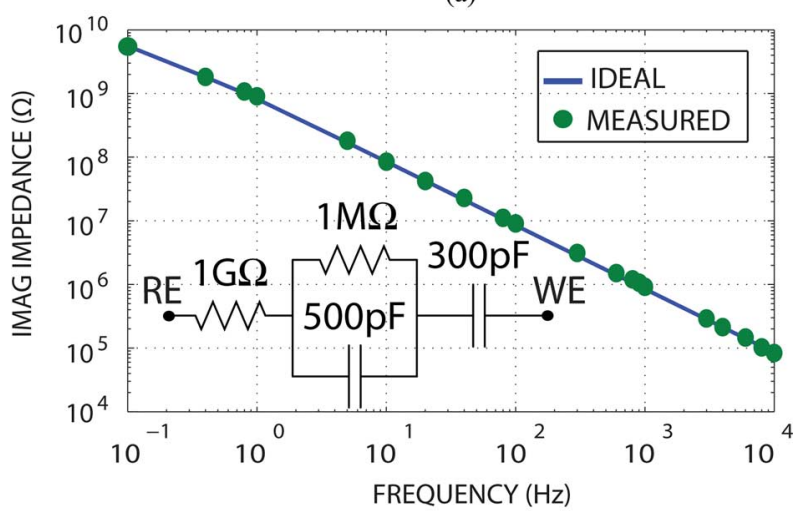

(b)

Fig. 20. Off-chip biosensor model impedance as a function of frequency experimentally measured by the impedance spectroscopy microsystem. (a) Real. (b) Imaginary components.

be set to a specific voltage independently, allowing for simultaneous detection of different DNA strands.

The digital output of one channel for the input current swept between $100 \mathrm{fA}$ and $400 \mathrm{nA}$ is shown in Fig. 15. The static input dynamic range is $140 \mathrm{~dB}$ cumulatively for the three sampling frequency settings, or $55.4 \mathrm{~dB}$ at $1 \mathrm{MHz}$ clock. The dynamic range for each setting is computed by taking the ratio of the maximum signal that saturates the ADC to the LSB for a given sampling frequency setting. Dynamic performance of an entire channel was measured by applying a $10 \mathrm{~Hz}$ full scale (400 nA)

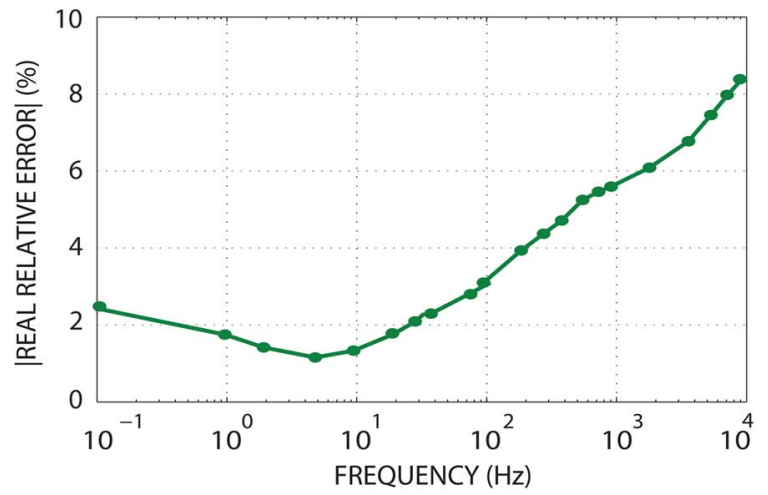

(a)

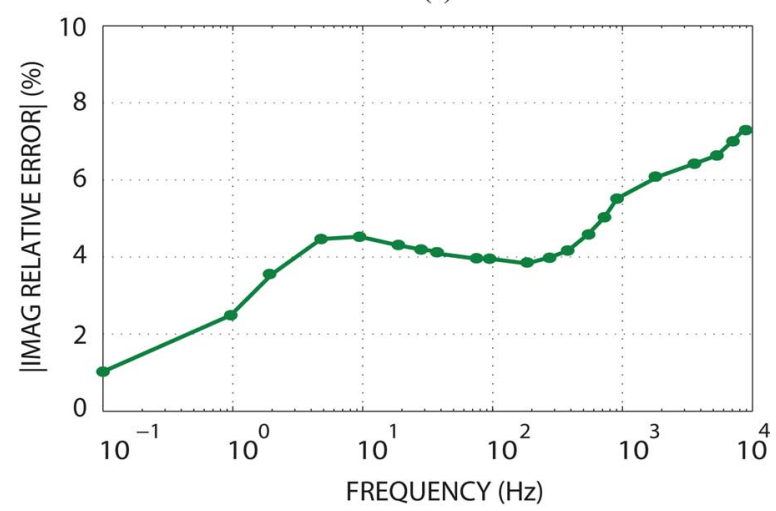

(b)

Fig. 21. Absolute value of the relative error of the off-chip biosensor model impedance as a function of frequency. (a) Real. (b) Imaginary components.

sinusoidal input current with the ADC clocked at $10 \mathrm{MHz}$. Fig. 16 shows the 65536-point FFT of the measured ADC output. The strong second harmonic is due to the single-ended architecture of the ADC. The resulting effective number of bits (ENOB) is 9.3. The DNL and INL of the waveform generator are shown in Figs. 17 and 18, respectively. The waveform generator achieves an static accuracy of 8 bits. Dynamic performance of the waveform generator was characterized by measuring the total harmonic distortion of the DAC versus frequency. Fig. 19 shows the THD of the measured DAC output. The DAC archives a THD of greater than $42 \mathrm{~dB}$ over the operating frequency range.

The electrode model shown in Fig. 1 was used first to emulate the biosensor. The value of $R_{S}$ was set to $1 \mathrm{G} \Omega, C_{W E}$ was set to $500 \mathrm{pF}, C_{D B}$ was set to $300 \mathrm{pF}$ and $R_{C T}$ was set to $1 \mathrm{M} \Omega$. To verify the impedance extraction capability of the microsystem, a sinusoidal voltage stimulus (generated by the on-chip DAC) with the frequency swept from $0.1 \mathrm{~Hz}$ to $10 \mathrm{kHz}$ was applied to the biosensor model. Fig. 20(a) and (b) demonstrate that the fabricated prototype tracks the theoretical model well over the full range of frequencies. The absolute value of the relative error of the ideal biosensor impedance verses the measured biosensor impedance as a function of frequency is shown in Fig. 21. The absolute value of the relative error stays below $8.4 \%$ and $7.5 \%$ for real and imaginary component of the biosensor respectively.

Table IV provides a summary of experimentally measured characteristics of the integrated impedance spectroscopy microsystem. 


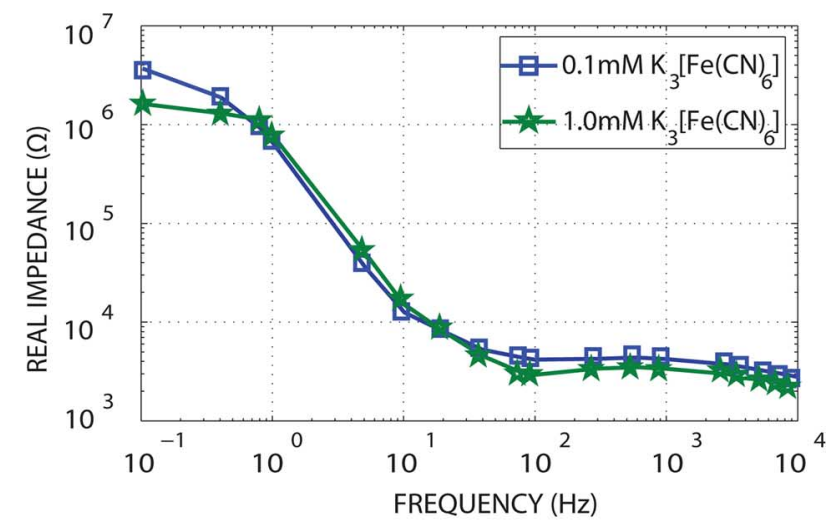

(a)

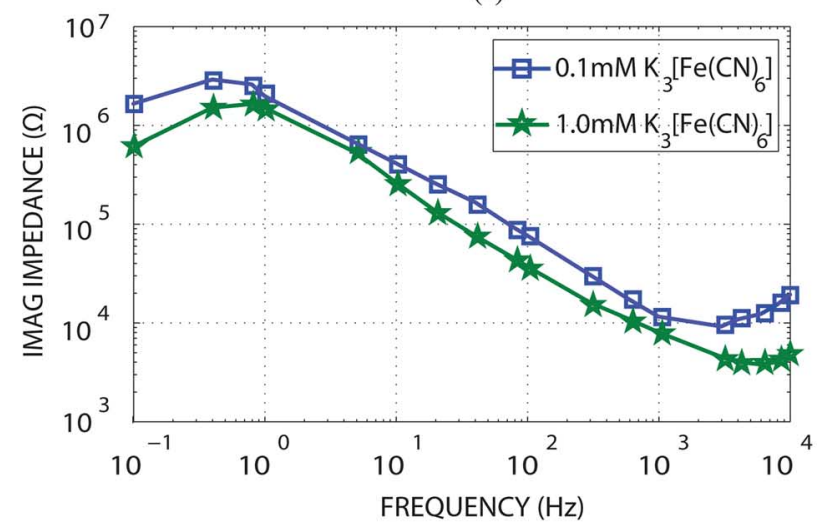

(b)

Fig. 22. Potassium ferricyanide solution impedance as a function of frequency experimentally measured by the impedance spectroscopy microsystem. (a) Real. (b) Imaginary components.

\section{ELECTROCHEMICAL EXPERIMENTAL RESULTS}

A set of electrochemical experiments have been conducted to validate the functionality of the impedance spectroscopy microsystem. In these tests a 3 -electrode setup has been utilized with on-chip gold-plated $55 \mu \mathrm{m} \times 55 \mu \mathrm{m}$ working electrode, on-chip gold plated counter electrode and an off-chip $\mathrm{Ag}-\mathrm{AgCl}$ reference electrode. The reference and counter electrodes are driven by the on-chip three-electrode regulation loop as shown in Fig. 13(a) and all the excitation waveforms are generated using the on-chip waveform generator.

First, in order to validate the design, impedance spectroscopy recordings of $0.1 \mathrm{mM}$ and $1 \mathrm{mM}$ potassium ferricyanide in $1 \mu \mathrm{M}$ potassium phosphate buffer ( $\mathrm{pH} 7.3$ ) were carried out. A $9 \mathrm{mV}$ $0.1 \mathrm{~Hz}$ to $10 \mathrm{kHz}$ sine wave was applied between the WEs and an off-chip $\mathrm{Ag}-\mathrm{AgCl}$ reference electrode. The real and imaginary impedance results obtained from the two concentrations of the potassium ferricyanide solution are shown in Figs. 22(a) and (b). An increase in the concentration of the potassium ferricyanide results in a decrease in value of $R_{S}$ and $R_{C T}$ and increase in value of $C_{W E}$. The measurements of potassium ferricyanide validate impedance spectroscopy microsystem in DNA sensing applications.

The $\mathrm{SoC}$ was also extensively validated in DNA analysis for detection of prostate cancer. Fig. 23(a) shows real and imaginary impedance components of an on-chip Au electrode hybridized with $5 \mu \mathrm{M}$ single-stranded prostate cancer probe DNA.

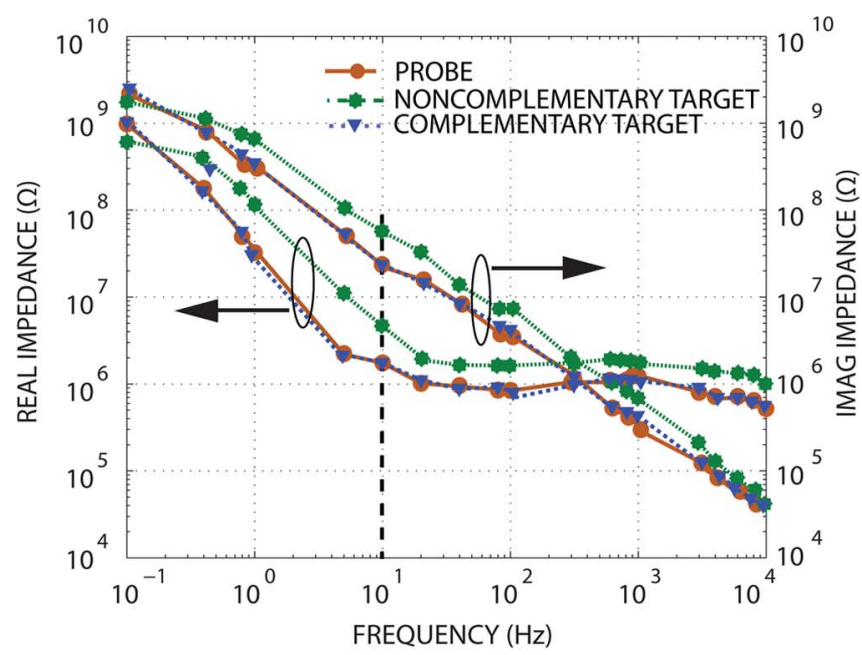

(a)
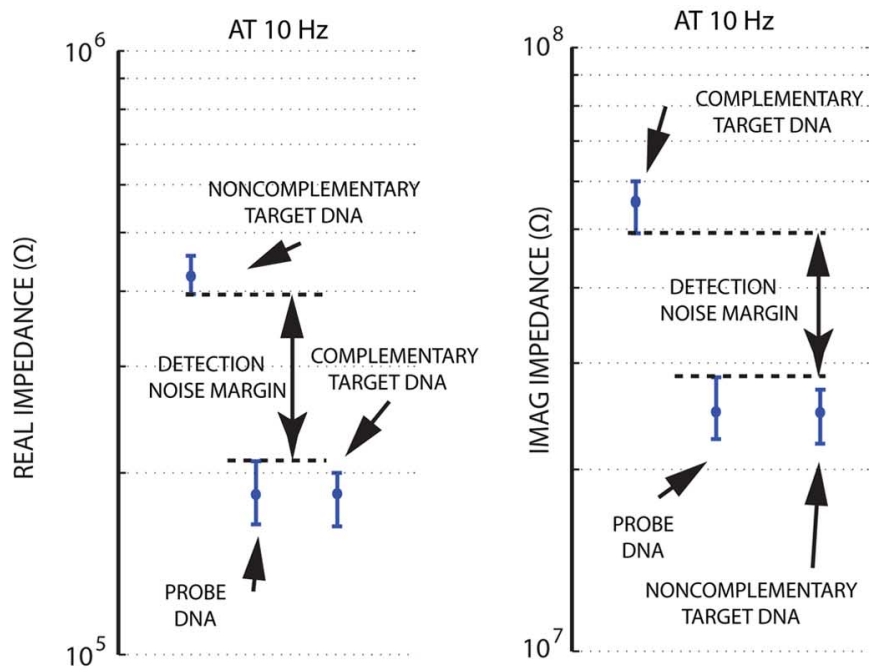

(b)

Fig. 23. (a) Impedance spectrum of $5 \mu \mathrm{M}$ prostate cancer DNA probe, complementary, and non-complementary targets. (b) The corresponding 3-sigma error bars (from 3 chips, 20 measurements each).

Adding a $5 \mu \mathrm{M}$ noncomplementary target DNA does not significantly change the real and imaginary components of the electrode impedance indicating that non-specific adsorption is negligible. Adding a $5 \mu \mathrm{M}$ complementary prostate cancer target DNA leads to significant reduction of potassium ferrocyanide redox current, resulting in increase in both real and imaginary components of the electrode impedance. This is due to the additional negative surface charge resulting from formation of double-stranded DNA on the electrode surface. The 3-sigma error bars (from 3 chips) with the real and imaginary impedance detection noise margins of approximately $18.3 \mathrm{~K} \Omega$ and $20.9 \mathrm{M} \Omega$ respectively are shown in Fig. 23(b).

Table $\mathrm{V}$ provides a comparative analysis of the presented design and existing amperometric biochemical sensory microsystems. The design presented in this work achieves the highest dynamic range and the lowest sensitivity in terms of LSB. Also, the design presented in this paper requires less time to extract real and imaginary components of the biosensor compared to 
TABLE V

COMPARATIVE ANALYSIS OF REPORTED AMPROMETRIC SENSORY MiCROSYSTEM

\begin{tabular}{|c|c|c|c|c|c|c|c|}
\hline 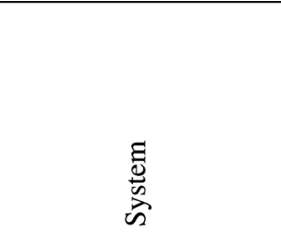 & $\begin{array}{l}\Xi \\
\Xi \\
0 \\
u \\
\cup \\
\varpi\end{array}$ & $\begin{array}{l}\infty \\
\infty \\
0 \\
\cup \\
\mathscr{\Omega} \\
\tilde{D}\end{array}$ & 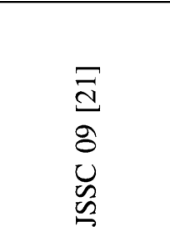 & 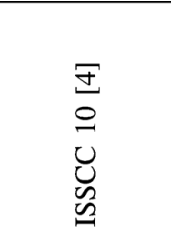 & $\begin{array}{l}\pi \\
0 \\
u \\
u \\
\approx \\
\approx\end{array}$ & $\begin{array}{l}\sigma \\
己 \\
5 \\
0 \\
\tilde{u} \\
0 \\
0 \\
0 \\
0\end{array}$ & 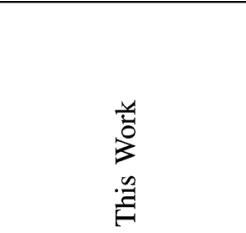 \\
\hline Technology(CMOS) & $0.18 \mu \mathrm{m}$ & $0.25 \mu \mathrm{m}$ & $0.5 \mu \mathrm{m}$ & $0.35 \mu \mathrm{m}$ & $0.6 \mu \mathrm{m}$ & $0.5 \mu \mathrm{m}$ & $0.13 \mu \mathrm{m}$ \\
\hline Power & $25 \mathrm{~mW}$ & $160 \mathrm{~mW}$ & $0.6 \mathrm{~mW}$ & $84.5 \mathrm{~mW}$ & - & $1.2 \mathrm{~mW}$ & $0.35 \mathrm{~mW}$ \\
\hline Supply Voltage & $5.0 \mathrm{~V}$ & $2.5 \mathrm{~V}$ & $3.0 \mathrm{~V}$ & $3.3 \mathrm{~V}$ & $3.3 \mathrm{~V}$ & $3.0 \mathrm{~V}$ & $1.2 \mathrm{~V}$ \\
\hline Chip Area & $11.2 \mathrm{~mm}^{2}$ & $15 \mathrm{~mm}^{2}$ & $2.25 \mathrm{~mm}^{2}$ & $4 \mathrm{~mm}^{2}$ & $25.8 \mathrm{~mm}^{2}$ & $9 \mathrm{~mm}^{2}$ & $1.68 \mathrm{~mm}^{2}$ \\
\hline $\begin{array}{l}\text { Electrode Count } \\
\text { Channel }\end{array}$ & 576 & 48 & 100 & 100 & 40 & 16 & 64 \\
\hline Channel Count & 24 & 16 & 100 & 100 & 40 & 16 & 16 \\
\hline Type Of & $2 \mathrm{D}$ & $2 \mathrm{D}$ & $2 \mathrm{D}$ & $2 \mathrm{D}$ & - & Off & $2 \mathrm{D}$ \\
\hline Electrodes & Polymer & Gold & Gold & Gold & - & Chip & Gold \\
\hline Power & - & $10 \mathrm{~mW}$ & $6 \mu \mathrm{W}$ & $0.84 \mathrm{~mW}$ & - & $4.3 \mu \mathrm{W}$ & $42 \mu \mathrm{W}$ \\
\hline Dynamic Range & - & $60 \mathrm{~dB}$ & $50 \mathrm{~dB}$ & $97 \mathrm{~dB}$ & $80 \mathrm{~dB}$ & - & 140dB (3-mode) \\
\hline Conversion Rate & $10 \mathrm{~Hz}$ & $10 \mathrm{kHz}$ & $10 \mathrm{kHz}$ & - & $1 \mathrm{~Hz}$ & $10 \mathrm{~Hz}$ & $10 \mathrm{kHz}$ \\
\hline Sensitivity(LSB) & $97 \mathrm{pA}$ & $240 \mathrm{pA}$ & - & $330 \mathrm{pA}$ & $25 \mu \mathrm{V}$ & - & $320 \mathrm{fA}$ \\
\hline ENOB & 11 bits & 9 bits & 8 bits & No ADC & 12 bits & 8 bits & 9.3 bits \\
\hline Waveform Generator & - & - & Yes & Yes & - & - & Yes \\
\hline Type & - & - & Square Wave & Square Wave & - & - & 8-bit Programmable \\
\hline Frequency & - & - & $10 \mathrm{KHz}$ & $50 \mathrm{MHz}$ & - & - & $10 \mathrm{kHz}$ \\
\hline Power & - & - & - & - & - & - & $1.1 \mathrm{~mW}(5 \mathrm{nF}$ Load) \\
\hline
\end{tabular}

the FRA implementations in which a square waveform is utilized for multiplication and integration. The stepwise approximation of the interrogation waveform and multiplication coefficients significantly reduces the systematic error caused by higher order harmonics present in the rectangular waveforms, thus eliminating the need for excessive averaging that is time consuming at the lower frequency range. This enables real-time monitoring and analysis of DNA hybridization.

\section{CONCLUSION}

A 16-channel, mixed-signal CMOS impedance spectroscopy DNA analyzer is presented. It consists of a programable waveform generator, on-chip memory and multiple impedance extraction units. Multiplication and integration, two operations required for frequency response analysis (FRA) algorithm, are efficiently performed by the in-channel current-mode input dualslope multiplying ADC with negligible resources overhead. The ADC combines impedance extraction and analog-to-digital conversion into a single conversion cycle. The impedance spectroscopy microsystem was implemented in a CMOS $0.13 \mu \mathrm{m}$ technology. Each channel occupies an area of $0.06 \mathrm{~mm}^{2}$ and consumes $42 \mu \mathrm{W}$ of power from a $1.2 \mathrm{~V}$ supply.

\section{REFERENCES}

[1] F. Heer, M. Keller, G. Yu, J. Janata, M. Josowicz, and A. Hierlemann, "CMOS electro-chemical DNA-detection array with on-chip ADC," in Proc. IEEE Int. Solid-State Circuits Conf., 2008, pp. 168-169.

[2] M. Schienle, C. Paulus, A. Frey, F. Hofmann, B. Holzapfl, P. S. Bauer, and R. Thewes, "A fully electronic DNA sensor with 128 positions and in-pixel A/D conversion," IEEE J. Solid-State Circuits, vol. 39, no. 12, pp. 2438-2445, 2004.

[3] D. M. Garner, H. Bai, P. Georgiou, T. G. Constandinou, S. Reed, L. M. Shepherd, W. Wong, K. T. Lim, and C. Toumazou, "A multichannel DNA SoC for rapid point-of-care gene detection," in Proc. IEEE Int. Solid-State Circuits Conf., 2010, pp. 492-493.
[4] A. Hassibi and T. H. Lee, "A programmable $0.18 \mu \mathrm{m}$ CMOS electrochemical sensor microarray for bimolecular detection," IEEE Sensors J., vol. 6, pp. 1380-1388, 2006.

[5] A. Hassibi, H. Vikalo, J. L. Riechmann, and B. Hassibi, "Real-time DNA microarray analysis," Nucl. Acids Res., pp. 1-12, Aug. 2009.

[6] B. Jang, P. Cao, A. Chevalier, A. Ellington, and A. Hassibi, "A CMOS fluorescence-based biosensor microarray," in Proc. IEEE Int. SolidState Circuits Conf., Feb. 2009, pp. 436-437.

[7] H. Wang, Y. Chen, A. Hassibi, A. Scherer, and A. Hajimiri, “A frequency-shift CMOS magnetic biosensor array with single-bead sensitivity and no external magnet," in Proc. IEEE Int. Solid-State Circuits Conf., Feb. 2009, pp. 438-439.

[8] P. M. Levine, P. Gong, R. Levicky, and K. L. Shepard, "Active CMOS sensor array for electrochemical biomolecular detection," IEEE J. Solid-State Circuits, vol. 43, no. 8, pp. 1859-1871, 2008.

[9] J. Wang, "Electrochemical nucleic acid biosensors," Analytica Chimica Acta, vol. 469, pp. 63-71, 2002.

[10] T. G. Drummond, M. G. Hill, and J. K. Barton, "Electrochemical DNA sensors," Nature Biotechnol., vol. 21, no. 10, pp. 1192-1199, Oct. 2003.

[11] D. A. D. Giusto, W. A. Wlassoff, S. Giesebrecht, J. J. Gooding, and G. C. King, "Enzymatic synthesis of redox-labeled RNA and dual-potential detection at DNA-modified electrodes," Angewandte Chemie Int. Ed., vol. 43, pp. 2809-2812, 2004.

[12] M. Schena, D. Shalon, R. W. Davis, and P. O. Brown, "Quantitative monitoring of gene expression patterns with a complementary DNA microarray," Science, vol. 270, no. 5235, pp. 467-470, Oct. 1995.

[13] C. Yang, Y. Huang, B. L. Hassler, R. M. Worden, and A. J. Mason, "Amperometric electrochemical microsystem for a miniaturized protein biosensor array," IEEE Trans. Biomed. Circuits Syst., vol. 3, no. 3, pp. $160-168,2009$.

[14] R. Genov, M. Stanacevic, M. Naware, G. Cauwenberghs, and N. Thakor, "16-channel integrated potentiostat for distributed neurochemical sensing," IEEE Trans. Circuits Syst. I, Reg. Papers, vol. 53, no. 11, pp. 2371-2376, Nov. 2006.

[15] M. Roham, M. P. Garris, and P. Mohseni, "A wireless IC for time-share chemical and electrical neural recording," IEEE J. Solid-State Circuits, vol. 44, no. 12, pp. 3645-3658, 2009.

[16] M. Stanacevic, K. Murari, A. Rege, G. Cauwenberghs, and N. Thakor, "VLSI potentiostat array with oversampling gain modulation for widerange neurotransmitter sensing," IEEE Trans. Biomed. Circuits Syst., vol. 1 , no. 1, pp. 63-72, Feb. 2007.

[17] M. Nazari and R. Genov, "A fully differential CMOS potentiostat," in Proc. IEEE Int. Symp. Circuits and Systems, May 2009, vol. 2, pp. 2177-2180. 
[18] M. Nazari, H. M. Jafari, and R. Genov, "192-channel CMOS neurochemical microarray," in proc. IEEE Custom Integrated Circuits Conf., Sep. 2010, pp. 121-125.

[19] J. Kafka, O. Pnke, B. Abendroth, and F. Lisdat, "A label-free DNA sensor based on impedance spectroscopy," Electrochimica Acta, vol. 53, no. 25 , pp. $7467-7474$, Oct. 2008.

[20] Y. T. Long, C. Z. Li, H. B. Kraatz, and J. S. Lee, “AC impedance spectroscopy of native DNA and M-DNA," Biophys. J., vol. 84, no. 5, pp. 3218-3225, May 2003.

[21] C. Yang, S. R. Jadhav, R. M. Worden, and A. J. Mason, "Compact lowpower impedance-to-digital converter for sensor array microsystems," IEEE J. Solid-State Circuits, vol. 44, no. 10, pp. 2844-2855, 2009.

[22] M. Min and T. Parve, "Improvement of lock-in bio-impedance analyzer for implantable medical devices," IEEE Trans. Instrum. Meas., vol. 56, pp. 968-974, 2007.

[23] A. Manickam, A. Chevalier, M. McDermortt, A. D. Ellington, and A. Hassibi, "A CMOS electrochemical impedance spectroscopy biosensor array for label-free biomolecular detection," in Proc. IEEE Int. SolidState Circuits Conf., 2010, pp. 130-131.

[24] E. Barsoukov and J. R. Macdonald, Impedance Spectroscopy: Theory Experiment, and Applications, 2nd ed. Hoboken, NJ: Wiley, 2005.

[25] M. Alubaidy, L. Soleymani, K. Venkatakrishnan, and B. Tan, "Femtosecond laser nanostructuring for femtosensitive DNA detection," Biosens. Bioelectron., vol. 33, no. 1, pp. 83-87, Mar. 2012.

[26] L. Aorga, A. Rebollo, J. Herrn, S. Arana, E. Bandrs, and J. Garca-Foncillas, "Development of a DNA microelectrochemical biosensor for CEACAM5 detection," IEEE Sensors J., vol. 10, no. 8, pp. 1368-1374, Aug. 2010.

[27] Y. S. Choi, K. S. Lee, and D. H. Park, "A genomic detection using an indicator-free DNA on a DNA chip microarray," Appl. Phys., vol. 6 , pp. 772-776, 2006.

[28] H. M. Jafari and R. Genov, "CMOS impedance spectrum analyzer with dual-slope multiplying ADC," in Proc. IEEE Biomedical Circuits and Systems Conf., San Diego, CA, Nov. 2011.

[29] L. Li, X. Liu, W. A. Qureshi, and A. J. Mason, "CMOS amperometric instrumentation and packaging for biosensor array applications," IEEE Trans. Biomed. Circuits Syst., vol. 5, no. 5, pp. 439-448, 2011.

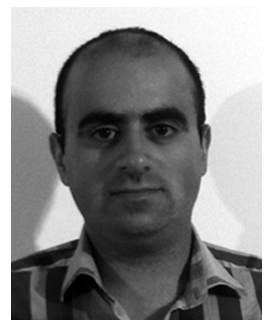

Hamed Mazhab-Jafari (S'11) received the B.Eng. and M.A.Sc. degrees in electrical engineering from McMaster University, Hamilton, ON, Canada, in 2004 and 2006, respectively.

$\mathrm{He}$ is currently working toward the Ph.D. degree in electrical and computer engineering at the University of Toronto, Toronto, ON, Canada. His M.A.Sc. thesis focused on low-power ultra-wideband CMOS front end and ultra-widebands antennas. His Ph.D dissertation focus is on CMOS DNA analysis SoC. He has held internship positions at Kapik Integration, where he worked on low-power mixed signal circuits. Since 2011, he has been with Snowbush IP, Toronto, ON, Canada, where he focuses on research and development of next-generation high-speed wireline communication systems.

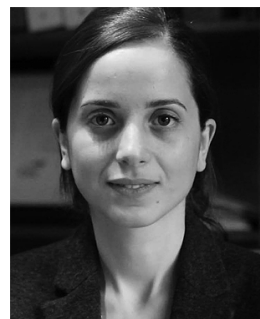

Leyla Soleymani received the Ph.D. degree in electrical and computer engineering from the University of Toronto, Toronto, ON, Canada, in 2010.

She is currently an Assistant Professor in the Department of Engineering Physics and School of Biomedical Engineering, McMaster University, Hamilton, ON, Canada. Her research interests include development of new hierarchical materials and combining different micro/nanofabrication technologies for building chip-based biosensors.

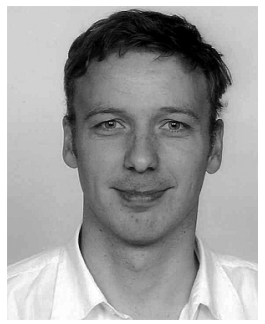

Roman Genov (S'96-M'02-SM'11) received the B.S. degree (first rank) in electrical engineering from the Rochester Institute of Technology, Rochester, NY, in 1996, and the M.S. and Ph.D. degrees in electrical and computer engineering from Johns Hopkins University, Baltimore, MD, in 1998 and 2002, respectively.

He held engineering positions at Atmel Corporation, Columbia, MD, in 1995 and Xerox Corporation, Rochester, NY, in 1996. He was a Visiting Researcher in the Laboratory of Intelligent Systems at the Swiss Federal Institute of Technology (EPFL), Lausanne, Switzerland, in 1998 and in the Center for Biological and Computational Learning at the Massachusetts Institute of Technology, Cambridge, in 1999. He is currently an Associate Professor in the Department of Electrical and Computer Engineering at the University of Toronto, Toronto, ON, Canada. His research interests include analog and digital VLSI circuits, systems and algorithms for energy-efficient signal processing with applications to electrical, chemical and photonic sensory information acquisition, biosensor arrays, brain-silicon interfaces, parallel signal processing, adaptive computing for pattern recognition, and implantable and wearable biomedical electronics.

Dr. Genov received the Canadian Institutes of Health Research (CIHR) Next GenerationAward in 2005, the Brian L. BargeAward for excellence in microsystems integration in 2008, the DALSA Corporation Award for excellence in microsystems innovation in 2006 and 2009, and the Best Paper Award on sensors and the Best Student PaperAward, both at the IEEE International Symposium on Circuits and Systems in 2009. He is an Associate Editor of IEEE TRANSACTIONS on BIOMEDICAL CIRCUITS AND SYSTEMS, IEEE TRANSACTIONS ON CIRCUITS AND Systems II: EXPRESS BRIEFS, and IEEE SIGNAL PROCESSING LETTERS. 